\title{
ROBUST SPEED SENSORLESS CONTROL OF FIVE-PHASE INDUCTION MOTOR DRIVE SYSTEM
}

\author{
Z. M. S. Elbarbary ${ }^{1}$ and S. A. Mahmoud ${ }^{2}$ \\ ${ }^{1}$ Faculty of Engineering - KFS University \\ ${ }^{2}$ Faculty of Engineering, Shebin El-Kom, Minoufiya University, Egypt
}

\begin{abstract}
Five -phase ac motor drives are nowadays considered for various applications, due to numerous advantages that they offer when compared to three-phase motors. Variable speed induction motor drives without mechanical speed sensors at the motor shaft have the attractions of low cost and high reliability. To replace the sensor, information of the rotor speed is extracted from measured stator currents and voltages at motor terminals. This paper proposes speed estimation method using model reference adaptive system (MRAS) to improve the performance of a sensorless vector controller of five-phase induction motor (IM). In the proposed method, the stator current is used as the state variable to estimate the speed. Since the stator current error is represented as a function of the first degree for the error value in the speed estimation, the proposed method can provide fast speed estimation and is also, more robust to variations in the parameters, compared with other MRAS methods. Consequently, this method can improve the performance of a sensorless vector controller in a low speed region and at zero-speed. The proposed method is verified by simulation using the Matlab/Simulink package. The performance of the proposed system is investigated at different operating conditions. The proposed controller is robust and suitable for high performance five-phase induction motor drives. Simulation results validate the proposed approaches.
\end{abstract}

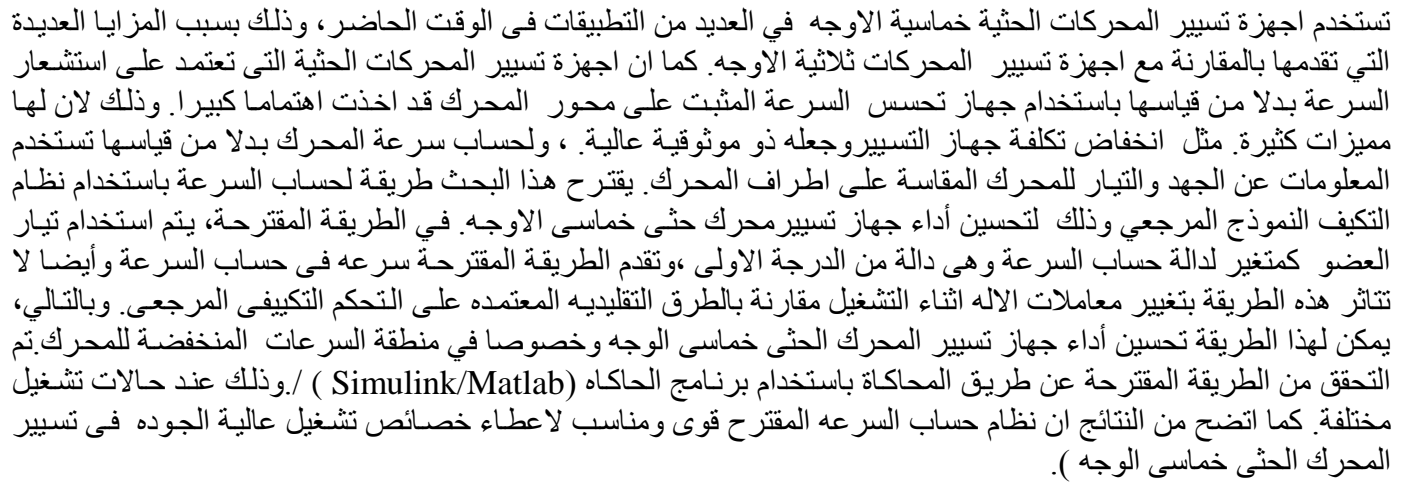

Keywords: Five-Phase Induction motor, Sensorless Vector control, Five -phase inverter, MRAS

\section{Nomenclature}

$\mathrm{L}_{\mathrm{ls}}$ : stator leakage inductance $(\mathrm{H})$

$\mathrm{L}_{\mathrm{m}}$ : magnetizing inductance $(\mathrm{H})$

$\mathrm{T}_{1}$ : load torque (N.m)

$\mathrm{J}$ : inertia of motor $\left(\mathrm{Kg} \cdot \mathrm{m}^{2}\right)$

B : friction coefficient (N.m.s/rad)
Rs : stator phase resistance (ohm)

$\mathrm{I}_{\mathrm{qs}}:$ stator quadrature axis current $(\mathrm{A})$

$\mathrm{I}_{\mathrm{ds}}:$ stator direct axis current $(\mathrm{A})$

$\mathrm{I}_{\mathrm{qr}}$ : rotor quadrature axis current $(\mathrm{A})$

$\mathrm{I}_{\mathrm{dr}}$ : rotor direct axis current $(\mathrm{A})$

$\mathrm{L}_{\mathrm{s}}$ : stator equivalent inductance $(\mathrm{H})$ 


\section{INTRODUCTION}

Over the years; induction motor (IM) has been utilized as a workhorse in the industry due to its easy build, high robustness, and generally satisfactory efficiency. Multi-phase machines have found wide applications in transport, textile manufacturing and aerospace since few years. In electrical drive applications, three-phase drives are widely used for their convenience. However, high-phase number drives possess several advantages over conventional three-phase drives such as: reducing the amplitude and increasing the frequency of torque pulsations, reducing the rotor harmonic currents, reducing the current per phase without increasing the voltage per phase, and lowering the dc-link current harmonics and higher reliability. By increasing the number of phases, it is also possible to increase the torque per rms ampere for the same machine volume [1-5].

Applications involving high power may require multiphase systems, in order to reduce stress on the switching devices. There are two approaches for supplying high power systems; one approach is the use of multilevel inverters supplying three-phase machines and the other approach is multi leg inverters supplying multiphase machines. Much more work has been done on multilevel inverters. It is interesting to note that the similarity in switching schemes between the two approaches: for the multilevel inverter the additional switching devices increase the number of voltage levels, while for the multi leg inverter, the additional number of switching devices increases the number of phases [6].The recent research works on multiphase machines can be categorized into multi-phase pulse width modulation (PWM) techniques for multiphase machines, harmonic injection to produce more torque and to achieve better stability [5], fault tolerant issues of multi-phase motor drives, series/ parallel connected multi-phase machines [6] .

In Ref. [7], an n-phase space vector PWM (SVPWM) scheme can be described in terms of the applying times of available switching vectors on the basis of the space vector concept. However, the paper only focuses on how to realize a sinusoidal phase voltage. Much research on control method and running performance of five-phase drive with twolevel inverter was made. Another research has been done on a multiphase two-level non-inusoidal SVPWM [8, 9]. The power rating of the converter should meet the required level for the machine and driven load. However, the converter ratings cannot be increased over a certain range due to the limitation of the power rating of semiconductor devices. One solution to this problem is using multilevel inverter, where switches of reduced rating are employed to develop high power level converters. The advent of inverter fed-motor drives also removed the limits of the number of motor phases. This fact made it possible to design machine with more than three phases and brought about the increasing investigation and applications of multiphase motor drives [10-13].

The five-phase induction motor drives have many more space voltage vectors than the three-phase induction motor drives. The increased number of vectors allows the generation of a more elaborate switching vector table, in which the selection of the voltage vectors is made based on the real-time values of the stator flux and torque variations.

In this paper, an indirect rotor field oriented based speed sensorless using MRAS control of high performance induction motor drive is proposed.

The proposed method can provide fast speed estimation and is also more robust to variations in the parameters compared with other MRAS methods. Consequently, the proposed MRAS method can improve the performance of a sensorless vector controller in a low speed region and at zero-speed.

The effectiveness of the proposed method is tested at different operating conditions. Simulation results are presented and discussed.

\section{DRIVE SYSTEM}

The control scheme of five- phase induction motor drive consists of the modeling of the five-phase IM, speed estimation, inverter, and an indirect rotor field oriented control of five-phase IM, which are discussed in the following subsections:

\subsection{Induction Motor Model}

Squirrel-cage five-phase induction motor is represented in its $\mathrm{d}-\mathrm{q}$ synchronous reference frame. The winding axes of five-stator winding are displaced by 72 degrees. By increasing the number of phases, it is also possible to increase the torque per ampere for the same machine volume. In this analysis the iron saturation is neglected.

The general equations of the five-phase induction motor can be introduced as follows:

The stator quadrature-axis voltage is given by:

$$
V_{q s}=R_{s} i_{q s}+\frac{d \lambda_{q s}}{d t}+\omega \lambda_{d s}
$$

The stator direct-axis voltage is given by:

$$
V_{d s}=R_{s} i_{d s}+\frac{d \lambda_{d s}}{d t}+\omega \lambda_{q s}
$$

For the stationary reference frame $\omega=0$, substitute into Equations (1) and (2) yields:

$$
\begin{aligned}
& V_{q s}=R_{s} i_{q s}+\frac{d \lambda_{q s}}{d t} \\
& V_{d s}=R_{s} i_{d s}+\frac{d \lambda_{d s}}{d t}
\end{aligned}
$$

The stator q-axis flux linkage is given by:

$$
\begin{aligned}
\lambda_{q s} & =L_{s} i_{q s}+L_{m} i_{q r} \\
& =\left(L_{l s}+L_{m}\right) i_{q s}+L_{m} i_{q r} \\
\lambda_{q s} & =L_{l s} i_{q s}+L_{m}\left(i_{q r}+i_{q s}\right)
\end{aligned}
$$


The stator d-axis flux linkage is given by:

$$
\begin{aligned}
\lambda_{d s} & =L_{s} i_{d s}+L_{m} i_{d r} \\
& =\left(L_{l s}+L_{m}\right) i_{d s}+L_{m} i_{d r} \\
\lambda_{d s} & =L_{l s} i_{d s}+L_{m}\left(i_{d r}+i_{d s}\right)
\end{aligned}
$$

The electromagnetic torque is given by:

$$
\begin{aligned}
& T_{e}=\frac{5}{2} \frac{p}{2}\left(\lambda_{d s} i_{q s}-\lambda_{q s} i_{d s}\right) \\
& T_{e}-T_{l}=j \frac{d \omega}{d t}+B \omega
\end{aligned}
$$

\subsection{Speed Estimation Based On MRAS}

Model Reference Adaptive Systems (MRAS) techniques are applied in order to estimate rotor speed. This technique is based on the comparison between the outputs of two estimators. The outputs of the two estimators may be rotor flux, back e.m.f. or motor reactive power. The estimator that does not involve the quantity to be estimated (the rotor speed $\omega r$ ) is considered as the induction motor voltage model. This model is considered to be the reference model (RM).And the other model is the current model, derived from the rotor equation, this model is considered to be the adjustable model (AM). The error between the estimated quantities by the two models is used to drive a suitable adaptation mechanism which generates the estimated rotor speed; $\omega r$ to be used in the current model was developed [14]. In this paper, the observer depends on the MRAS and speed observer based on stator current and rotor flux is shown in Figure 1. The stator current is represented as:

$$
\begin{aligned}
& i_{d s}=\frac{1}{L m}\left[\lambda_{d r}+\omega_{r} T_{r} \lambda_{q r}+T_{r} p \lambda_{d r}\right] \\
& i_{q s}=\frac{1}{L m}\left[\lambda_{q r}-\omega_{r} T_{r} \lambda_{q r}+T_{r} p \lambda_{q r}\right]
\end{aligned}
$$

Using the above equations, the stator current is estimated as;

$$
\begin{aligned}
& \hat{i}_{d s}=\frac{1}{L m}\left[\lambda_{d r}+\hat{\omega}_{r} T_{r} \lambda_{q r}+T_{r} p \lambda_{d r}\right] \\
& \hat{i}_{q s}=\frac{1}{L m}\left[\lambda_{q r}-\hat{\omega}_{r} T_{r} \lambda_{q r}+T_{r} p \lambda_{q r}\right]
\end{aligned}
$$

The difference in the stator current is obtained as;

$$
\begin{aligned}
& i_{d s}-\hat{i}_{d s}=\frac{T_{r}}{L m} \lambda_{q r}\left[\omega_{r}-\widehat{\omega}_{r}\right] \\
& \hat{i}_{q s}-i_{q s}=\frac{T_{r}}{L m} \lambda_{d r}\left[\omega_{r}-\widehat{\omega}_{r}\right]
\end{aligned}
$$

Multiplying equations (10) and (11) by the rotor flux and adding them together the following equation can be obtained;

$$
\begin{aligned}
& \left(i_{d s}-\hat{i}_{d s}\right) \lambda_{q r}=\frac{T_{r}}{L m} \stackrel{2}{\lambda}_{q r}\left[\omega_{r}-\widehat{\omega}_{r}\right] \\
& \left(\hat{i}_{q s}-i_{q s}\right) \lambda_{d r}=\frac{T_{r}}{L m} 2_{d r}^{2}\left[\omega_{r}-\widehat{\omega}_{r}\right]
\end{aligned}
$$

By summing the above two equations.

$$
\left(i_{d s}-\hat{i}_{d s}\right) \lambda_{q r}+\left(\hat{i}_{q s}-i_{q s}\right) \lambda_{d r}=\frac{T_{r}}{L m}\left(2^{2}{ }_{q r}+2_{d r}\right)\left[\omega_{r}-\hat{\omega}_{r}\right]
$$

Hence, the error of the rotor speed is obtained as follows:

$$
\begin{aligned}
& \omega_{r}-\hat{\omega}_{r}=\left[\left(i_{d s}-\hat{i}_{d s}\right) \lambda_{q r}-\left(i_{q s}-\hat{i}_{q s}\right) \lambda_{d r}\right] / K \\
& \text { Where } \quad K=\frac{T_{r}}{L m}\left(\hat{\lambda}_{q r}+\hat{\lambda}_{d r}\right)
\end{aligned}
$$

The right hand term seems as the term of speed calculation from adaptive observer, so the speed can be calculated from the following equation:

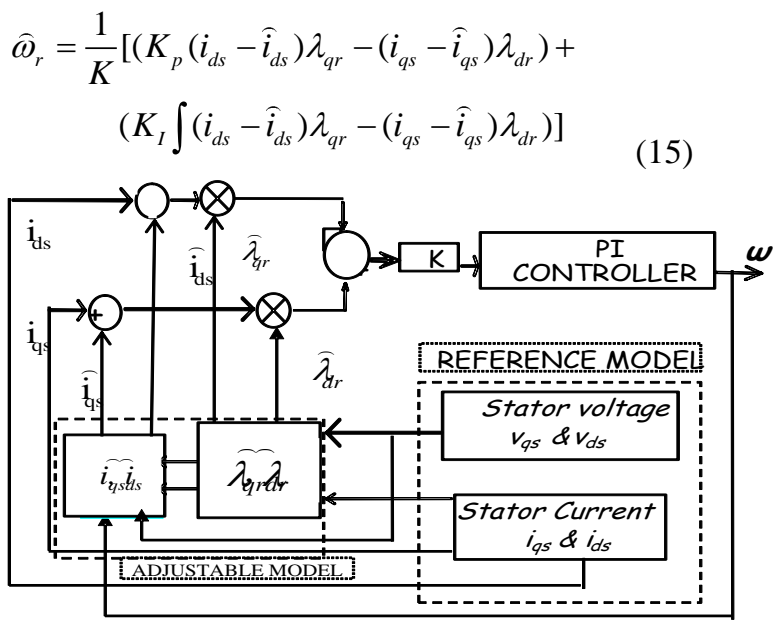

Fig.1 MRAS speed estimation scheme

\subsection{Overall System Controller}

The theory of indirect field oriented control is applied for the Five-phase induction motor. The application of the vector control scheme to such arrangement is simple, and can provide fastdecoupled control of torque and flux. In Fig.(2), the

estimated motor speed, $\omega_{m}$ is compared to a command speed, $\omega^{*}$, and the error signal is processed by the PI controller, to generate the torque-component current command Iq*. The fluxcomponent current command $\mathrm{Id}^{*}$ is calculated according to adopted control strategy. The two current command components are then transformed with the help of rotor position encoder (for angle $\theta \mathrm{e}$ ) to five current commands ia, ib ic, ie and ie in the stationary reference frame. These current commands are then compared to the actual motor currents by hysteresis current controller to generate the logic pulses for the inverter switches. 
The torque producing current component is calculated from the following equations:

$$
\begin{aligned}
& I_{q s}^{*}=\frac{1}{k_{t}} \frac{\left(\omega_{\mathrm{r}}^{*}-\omega_{r}\right)}{\lambda_{d r}^{*}} \frac{K_{p s}\left[1+\tau_{c s} S\right]}{\tau_{c s} S} \\
& I_{d s}^{e^{*}}=\frac{1}{L_{m}}\left(1+\tau_{r} * p\right) \lambda_{d r}^{e^{*}}
\end{aligned}
$$

The angular slip frequency command

$$
\begin{aligned}
& \left(\omega_{s l}^{*}\right) \text { is: } \\
& \omega_{s l}^{*}=\frac{L_{m}}{\tau_{r}^{*}} \cdot \frac{I_{q s}^{*}}{\lambda^{*} d r}
\end{aligned}
$$

Where, ${ }^{\tau} r$ is the rotor time constant and ${ }^{\lambda} d r$ is the direct-axis rotor flux. The angular frequency is obtained as follows,

$$
\begin{aligned}
& \omega_{e}^{*}=\omega_{s l}^{*}+\omega_{m} \\
& \theta_{e}^{*}=\int \omega_{e}^{*} \cdot d t \\
& T_{e}=K_{t}\left|\lambda_{d r}^{e}\right| I_{q s}^{e}
\end{aligned}
$$

Equation (21) is similar to that of the separately excited dc motor and denotes that the torque can initially proportional to the quadrature component of the stator current, ${ }^{* e}{ }^{* e}$, if the qe-axis component of the flux becomes zero (de-axis is aligned with the rotor flux axis), and the de-axis component ${ }_{\mathrm{dr}}^{\mathrm{e}}$ is kept constant. This is the philosophy of the vector control technique. The transformations used for the present system are expressed as follows;

$$
\mathrm{q}^{\mathrm{e}}-\mathrm{d}^{\mathrm{e}} \rightarrow \mathrm{q}^{\mathrm{s}}-\mathrm{d}^{\mathrm{s}}\left\{\begin{array}{l}
\mathrm{i}_{\mathrm{qs}}^{\mathrm{s}^{*}}=\mathrm{i}_{\mathrm{qs}}^{\mathrm{e}^{*}} \cos \theta_{\mathrm{s}}+\mathrm{i}_{\mathrm{ds}}^{\mathrm{e}^{*}} \sin \theta_{\mathrm{s}} \\
\mathrm{i}_{\mathrm{ds}}^{\mathrm{s}^{*}}=-\mathrm{i}_{\mathrm{qs}}^{\mathrm{e}^{*}} \sin \theta_{\mathrm{s}}+\mathrm{i}_{\mathrm{ds}}^{\mathrm{e}^{*}} \cos \theta_{\mathrm{s}}
\end{array}\right\}
$$

where $\theta_{\text {s }}$ represents the sum of the slip and rotor angles.

$$
\mathrm{q}^{\mathrm{s}} \mathrm{d}^{\mathrm{s}} / \operatorname{abced}\left\{\begin{array}{l}
\mathrm{i}_{\mathrm{as}}^{\mathrm{s}^{*}}=\mathrm{i}_{\mathrm{qs}}^{\mathrm{s}^{*}} \cos (\theta)+\mathrm{i}_{\mathrm{ds}}^{\mathrm{s}^{*}} \sin (\theta) \\
\mathrm{i}_{\mathrm{bs}}^{\mathrm{s}^{*}}=\mathrm{i}_{\mathrm{qs}}^{\mathrm{s}^{*}} \cos \left(\theta-\frac{2 \pi}{5}\right)+\mathrm{i}_{\mathrm{ds}}^{\mathrm{s}^{*}} \sin \left(\theta-\frac{2 \pi}{5}\right) \\
\mathrm{i}_{\mathrm{cs}}^{*}=\mathrm{i}_{\mathrm{qs}}^{\mathrm{s}^{*}} \cos \left(\theta-\frac{4 \pi}{5}\right)+\mathrm{i}_{\mathrm{ds}}^{\mathrm{s}^{*}} \sin \left(\theta-\frac{4 \pi}{5}\right) \\
\mathrm{i}_{\mathrm{ds}}^{\mathrm{s}^{*}}=\mathrm{i}_{\mathrm{qs}}^{\mathrm{s}^{*}} \cos \left(\theta+\frac{4 \pi}{5}\right)+\mathrm{i}_{\mathrm{ds}}^{\mathrm{s}^{*}} \sin \left(\theta+\frac{4 \pi}{5}\right) \\
\mathrm{i}_{\mathrm{es}}^{\mathrm{s}^{*}}=\mathrm{i}_{\mathrm{qs}}^{\mathrm{i}^{*}} \cos \left(\theta+\frac{2 \pi}{5}\right)+\mathrm{i}_{\mathrm{ds}}^{\mathrm{s}^{*}} \sin \left(\theta+\frac{2 \pi}{5}\right)
\end{array}\right\}
$$

\subsection{Five-phase inverter}

The modulated phase voltages of five-phase inverter fed five-phase induction motor are introduced as a function of switching logic NA, NB, $\mathrm{NC}, \mathrm{ND}$ and NE of power switches by the following relations:

$$
\left[\begin{array}{l}
V_{a s} \\
V_{b s} \\
V_{c s} \\
V_{d s} \\
V_{e s}
\end{array}\right]=\frac{V_{d c}}{5}\left[\begin{array}{ccccc}
4 & -1 & -1 & -1 & -1 \\
-1 & 4 & -1 & -1 & -1 \\
-1 & -1 & 4 & -1 & -1 \\
-1 & -1 & -1 & 4 & -1 \\
-1 & -1 & -1 & -1 & 4
\end{array}\right]\left[\begin{array}{l}
N A \\
N B \\
N C \\
N E \\
N D
\end{array}\right]
$$

The per-phase switching state having a range of $\mathrm{N}=$ 0 or 1

\section{RESULTS AND DISCUSSION}

The proposed control system shown in Fig. (2) is designed for a simulation investigation. Simulation is carried out using the general purpose simulation package Matlab/Simulink [15], Simulation results are presented to show the effectiveness of the proposed scheme at different operating conditions. These results are classified into two categories; the first represents start-up and steady-state while the second represents the dynamic performance

\subsection{Starting and Steady-State Performance}

The simulation results for start-up and steady-state performance are illustrated by Figs. 3 to 5. Figure 3.a shows the variation of motor estimated speed from start-up to the steady state speed $(150 \mathrm{rad} / \mathrm{sec})$, which is reached after about $100 \mathrm{~m} \mathrm{sec}$, whereas Figure 3 shows measured speed signal whares, Fig. 4 shows its estimated corresponding signal These results show a good correlation between the estimated speed signal and its corresponding measured.

In the two figures, signals are almost correlated from start-up point up to the steady state value, which is reached after about $100 \mathrm{~m} \mathrm{sec}$. Figure.3.c shows the error between the real motor speed and the estimated one when the stator resistance is $100 \%$ of its nominal value, that is, $7.4826 \Omega$, whereas fig.4.d shows the speed error when the stator resistance was increased to $135 \%$, that is, from 7.4826 to $10 \Omega$. As shown in Fig. $3 \mathrm{c}$ and $\mathrm{d}$, the speed estimation error of the proposed method is constant at $0.5 \mathrm{rad} / \mathrm{sec}$. It's a small value. Hence, the proposed method is robust to stator resistance variation. The motor phase current signals and developed torque corresponding to startup period is shown in Figures. $4 \mathrm{~b}$ and a respectively. The current signals are of sine wave profiles on which controller switching transients are shown. 


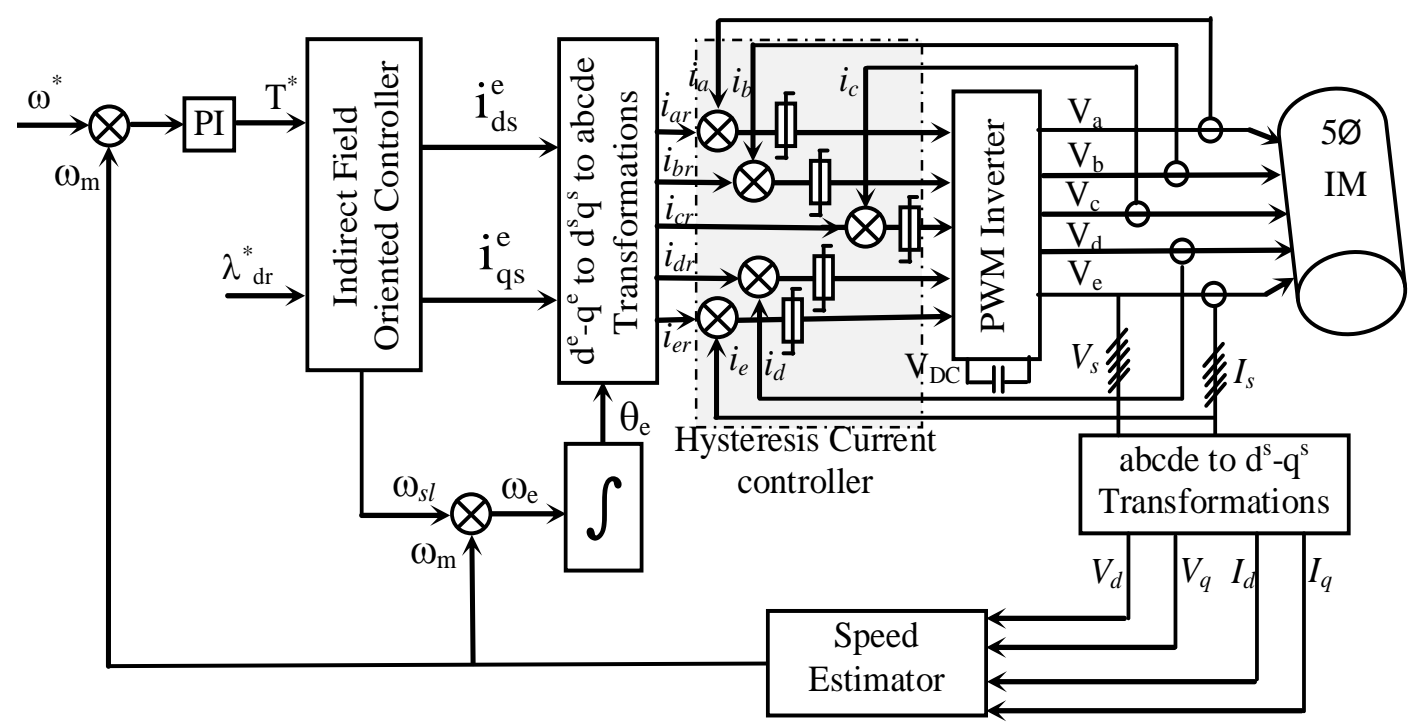

Fig. 2 Block Diagram of the Proposed Speed Control System

\subsection{Dynamic Performance}

For studying the dynamic performances of proposed system, a simulations has been carried out. In this respect, the dynamic response of the proposed speed estimation algorithm is studied at speed reversal under full load condition and load impact.

\subsubsection{Speeds Reversal}

To study the dynamic response of the control system due to speed reversal, the motor is subjected to speed reversal in the speed command to evaluate its the performance. At $\mathrm{t}=1.5$ second the motor speed command is reversal from $150 \mathrm{rad} / \mathrm{sec}$ to -150 $\mathrm{rad} / \mathrm{sec}$. Figure $5 \mathrm{a}$ and $\mathrm{b}$ shows the motor speed signals corresponding to this changes. It can be seen that the motor speed is accelerated smoothly with nearly zero steady state error in both direction. Figure 5.a shows measured speed signals whereas, Figure 5.b shows the estimated speed signal. These results show a good correlation between the estimated speed signal and its corresponding measured during speed reversal. This result is of special interest since it passes through low and zero speed and preserves good speed estimation which verifies the effectiveness of the proposed estimator to estimate the motor speed. Figure 5.c shows the speed error when the stator resistance was increased to $135 \%$, that is, from 7.4826 to $10 \Omega$. As shown in Fig. $5 \mathrm{c}$, the speed estimation error of the proposed method is constant at $\pm 0.5 \mathrm{rad} / \mathrm{sec}$ in both direction. This value ensures the robustness of the proposed speed estimation method to stator resistance variation. The motor phase current signals and developed torque corresponding to this speed reversal are shown in Figs. $6 \mathrm{~b}$ and a respectively. These results ensure the effectiveness of the proposed controller and shows good behavior of its dynamic response.

\subsubsection{Load Impact}

The ability to withstand disturbances in IM control system is another important feature. A step change in the motor load is considered as a typical disturbance. A high performance control system has fast dynamic response in adjusting its control variables so that, the system outputs affected by the load impact will recover to the original status as soon as possible. The dropped aptitude of the system output such as rotor speed and its recovering time are the important performance specifications. Figure 7 shows the speed response when a full load impact is applied for one second. The motor started at no load and the full load, is applied for one second. The corresponding developed torque is shown in Fig8a. Fig.8b show motor phase current, which increases with loading and decreases with load release.

\section{CONCLUSION}

This paper presents a robust rotor speed estimation method using MRAS to improve the performance of a sensorless vector controller of five- induction motor. The effectiveness of the proposed speed estimation algorithm has been investigated under dynamic and steady-state operation. A good correlation between simulated and measured speed signals has been obtained under different operating conditions. Also, the proposed speed estimation method gives special interest since it passes through low and zero speed and preserves good speed estimation and it is robust to variations in the stator resistance. The results show the effectiveness and robustness of the proposed speed estimation procedure. As a result, the proposed method can produce an excellent speed estimation performance in a low speed region and at zero-speed. 
Z.M.S. Elbarbary and S. A. Mahmoud "Robust Speed Sensorless Control of Five-Phase ..."

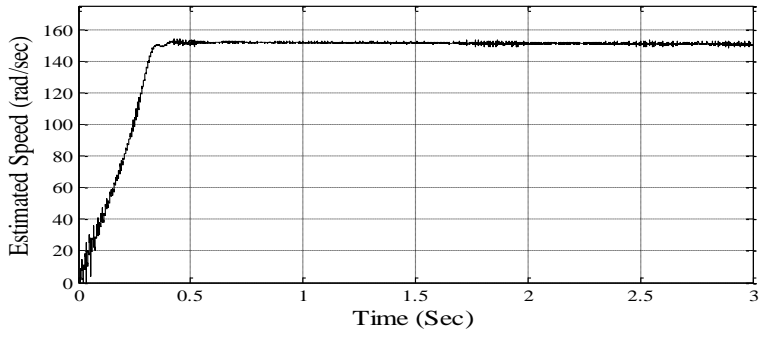

(a)

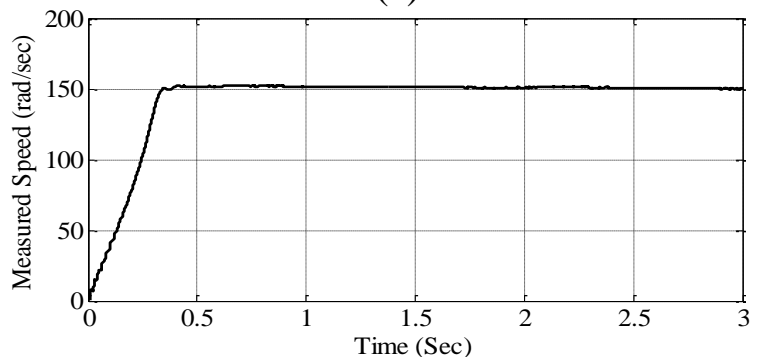

(b)

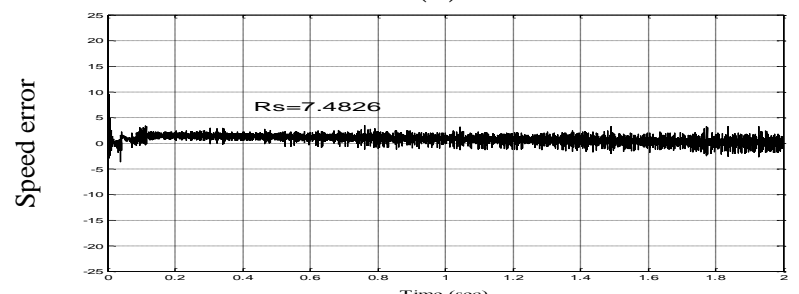

(c)

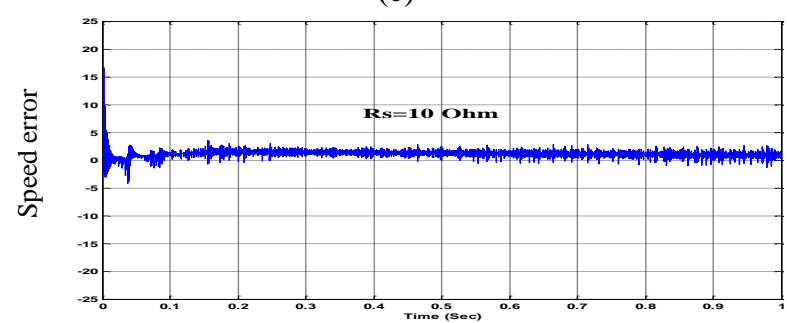

(d)

Fig.3 Start up (a) Estimated (b) Measured speed (c) Speed error at100\% Rs (d) speed error at $135 \%$ Rs

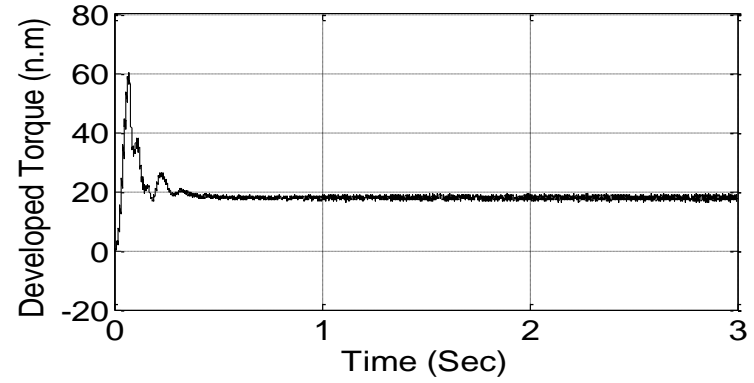

(a)

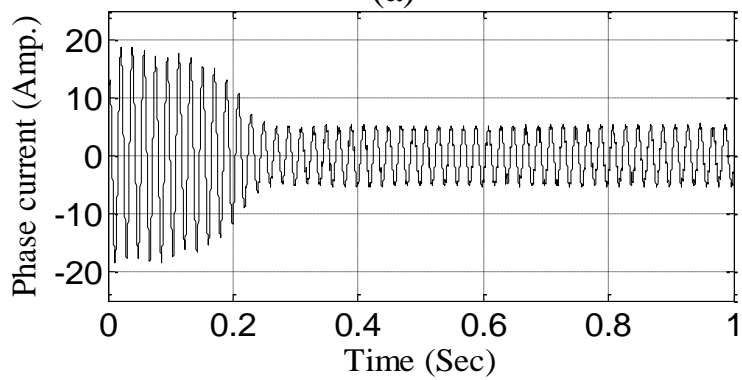

(b)

Fig.4 Start up (a) Torque (b) Phase current

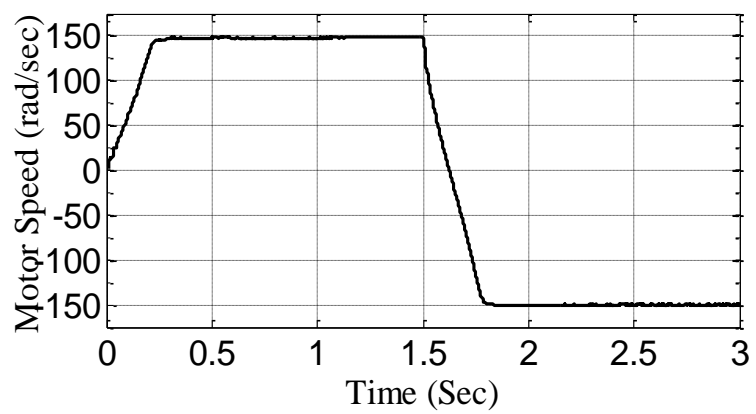

(a)

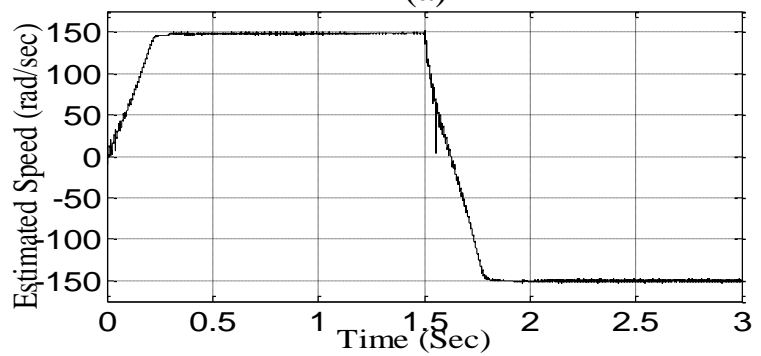

(b)

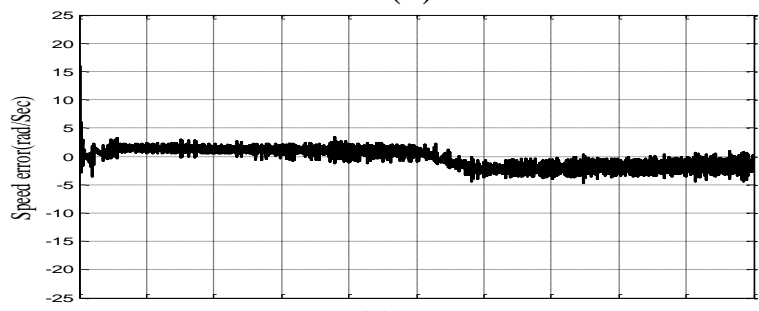

(c)

Fig.5 Speed Reversal (a) Estimated (b) Measured speed $(\mathrm{c})$ speed error $=( \pm 0.5 \mathrm{rad} / \mathrm{sec})$ 
Z.M.S. Elbarbary and S. A. Mahmoud "Robust Speed Sensorless Control of Five-Phase ..."

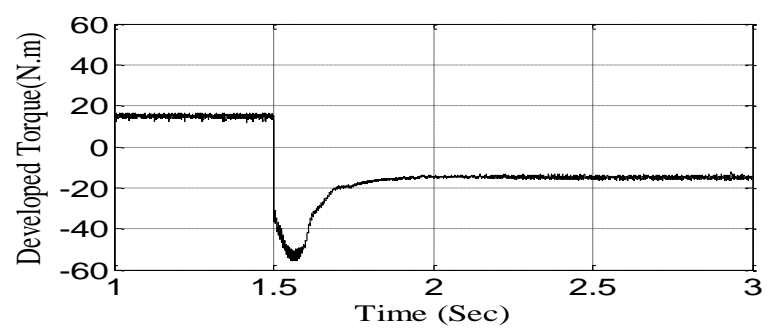

(a)

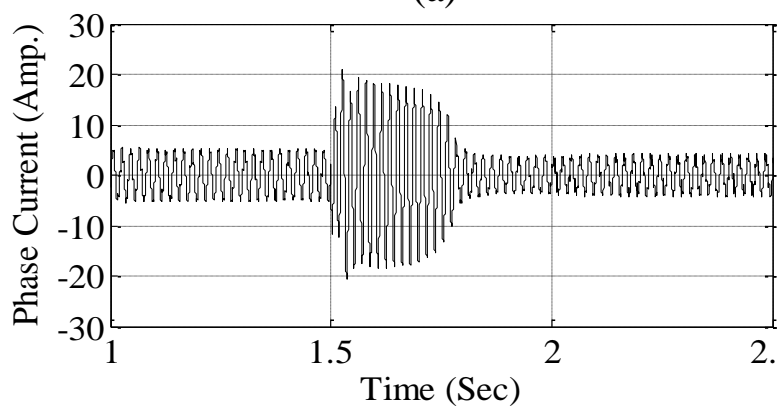

(b)

Fig. 6 Speed Reversal (a) Torque (b) Phase current

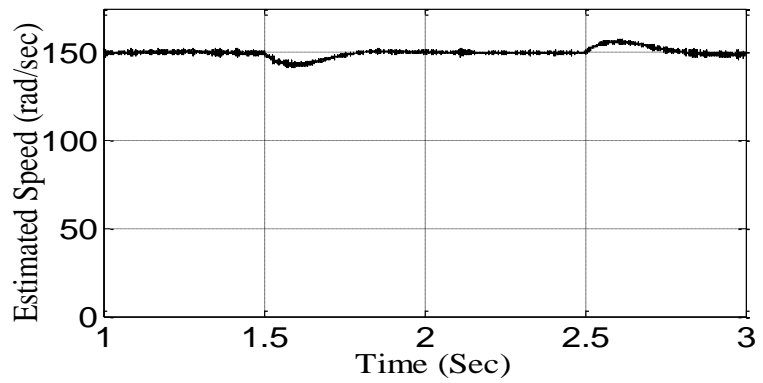

(a)

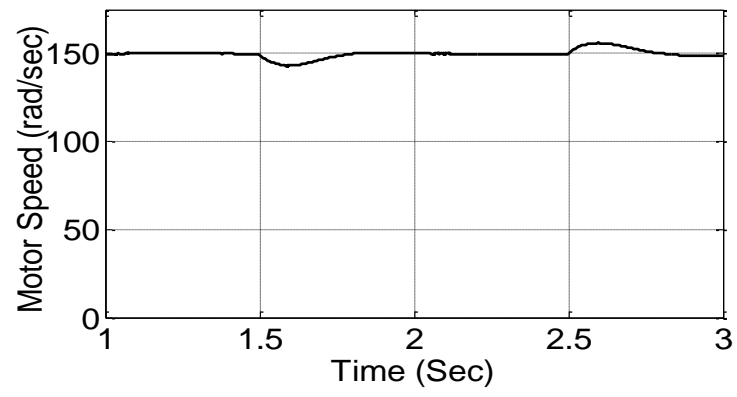

(b)

Fig. 7 Load Impact (a) Estimated (b) Measured speed

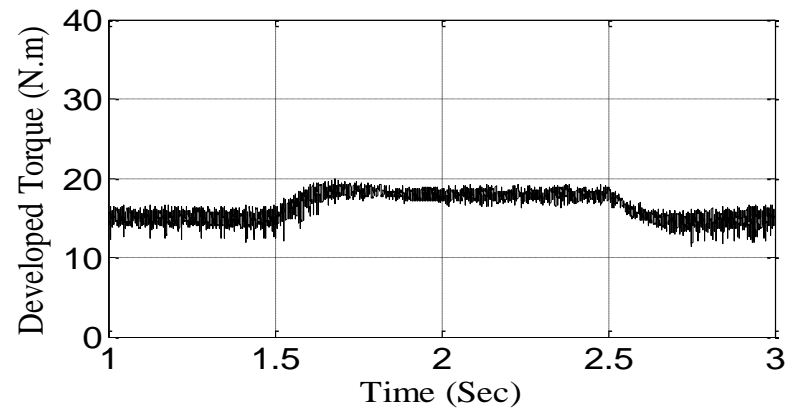

(a)

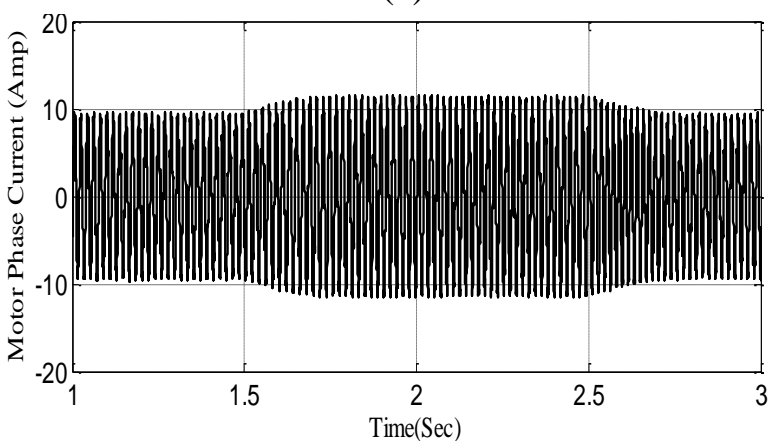

(b)

Fig. 8 Load Impact (a) Torque (b) Phase current

\section{REFERENCES}

[1] Levi, E., Bojoi, R., Profumo, F., Toliyat, H.A., and Williamson, S., "Multiphase induction motor drives technology status review"' IEE Elec. Power appl., 2007, (in press).

[2] Singh, G.K., "Multi-phase induction machine drive research - a survey", Electric Power Systems Research, 61, pp. 139-147,2002.

[3] E. E. Ward and H. Härer, "Preliminary investigation of an inverter-fed 5-phase induction motor," Proc. IEE, Vol. 116,No. 6, pp. 980-984, 1969

[4] Williamson, S., and Smith, A.C., "Pulsating torque and losses in multiphase induction machines", IEEE Trans. on Industry Applications, vol. 39, no. 4, pp. 986-993, 2003.

[5] G.D. Holmes, T.A. Lipo, "Pulse Width Modulation for Power Converters - Principles and Practice," IEEE Press Series on Power Engineering, John Wiley and Sons, Piscataway, NJ, USA, 2003.

[6] Toliyat, H.A., Waikar, S.P., and Lipo, T.A., 'Analysis of simulation of five-phase synchronous reluctance machines including third harmonic air gap MMF', IEEE Trans. On Industry Applications, vol. 34, no. 2, pp. 332339, 1998.

[7] Xu, H., Toliyat, H.A., and Petersen, L.J., 'Rotor field oriented control of a five-phase induction motor with the combined fundamental and third harmonic currents', Proc. IEEE Applied Power 
Electronics Conference APEC, Anaheim, CA, pp. 392-398, 2001.

[8] Xu, H., Toliyat, H.A., and Petersen, L.J., 'Fivephase induction motor drives with DSP-based control system', IEEE Trans. on Power Electronics, vol. 17, no. 2, pp. 524-533,2002.

[9] G.Grandi, G.Serra, A.Tani, "Space vector modulation of a seven-phase voltage source inverter", in Proc. Int. Symp. On Power Electronics, Electrical Drives, Automation and Motion SPEEDAM, Taormina, Italy, 2006, pp. S8-6-S8-13.

[10] J.W. Kelly, E.G. Strangas, J.M. Miller, "Multiphase space vector pulse width modulation," IEEE Trans. on Energy Conversion, vol. 18, no. 2, 2003, pp. 259-264.

[11] G.Grandi, G.Serra, A.Tani, "General analysis of multi-phase systems based on space vector approach", in Proc. EPEPEMC Conf., Portoroz, Slovenia, 2006, pp. 834-840.

[12]Durán, M.J., Levi, E. "Multi-dimensional approach to multiphase space vector modulation" in Proceedings IEEE 32nd Annual Conference of the IEEE Industrial Electronics Society. IECON, Paris, France, 2006.

[13] Toliyat, H.A., Shi, R., Xu, H., "A DSP-based vector control of five-phase synchronous reluctance motor", Proc. IEEE IAS Annual Meeting, Rome, Italy, 2000, CD-ROM paper No.40_05.

[14] Chul-Woo Park, Woo-Hyen Kwon "Simple and robust speed sensorless vector control of induction motor using stator current based MRAC" Electric Power Systems Research 71, pp. 257-266, 2004.

[15] Matlab/Simulink Toolbox User's Guide, The Math works Inc., Natick, MA, USA, May 1998.

\section{APPENDIX}

\section{Motor Parameter}

\begin{tabular}{|lc|}
\hline No. of poles & 4 \\
Stator resistance & $7.4826 \mathrm{ohm}$ \\
Rotor resistance & $3.6840 \mathrm{ohm}$ \\
Rotor leakage inductance & $0.0221 \mathrm{H}$ \\
Stator leakage inductance & $0.0221 \mathrm{H}$ \\
Mutual inductance & $0.4114 \mathrm{H}$ \\
Supply frequency & $50 \mathrm{~Hz}$ \\
Motor speed & $1500 \mathrm{r} . \mathrm{p} . \mathrm{m}$. \\
Supply voltage & $380 \mathrm{volts}$ \\
Inertia & $0.02 \mathrm{~kg} . \mathrm{m} 2$ \\
\hline
\end{tabular}

